\title{
Analytical Solution for the Deformation and Support Parameters of Coal Roadway in Layered Roof Strata
}

\author{
Kai Wang $\mathbb{D}^{1,2}$ Bao-gui Yang, ${ }^{1}$ Zhong-kui Wang, ${ }^{2}$ and Xiao-long Wang ${ }^{1}$ \\ ${ }^{1}$ School of Energy and Mining Engineering, China University of Mining \& Technology, Beijing 100083, China \\ ${ }^{2}$ Gucheng Coal Mine of Shanxi Lu'an Mining Group, Changzhi, Shanxi 046204, China \\ Correspondence should be addressed to Kai Wang; 2024613980@qq.com
}

Received 28 June 2021; Revised 17 August 2021; Accepted 9 October 2021; Published 25 October 2021

Academic Editor: Afshin Davarpanah

Copyright (C) 2021 Kai Wang et al. This is an open access article distributed under the Creative Commons Attribution License, which permits unrestricted use, distribution, and reproduction in any medium, provided the original work is properly cited.

\begin{abstract}
In order to meet the security and high-efficiency production needs, high-strength bolt (cable) reinforcement technology is usually used to maintain the stability of roadways. However, due to the great variability of lithology and mechanical properties, the failure form and stability of the layered roof in coal roadways are significant differences. The traditional supporting design method of the layered roof support in coal roadways is the engineering analogy method, which depends on experiences rather than theoretical analysis. Based on the theory of the elastic foundation beam and key stratum, this paper establishes a simplified analytical model of layered roof strata in coal roadways. Based on the Mohr-Coulomb theory, this paper gives the failure criteria of the layered roof strata, and the failure range of the layered roof strata is obtained. The length and pretightening force of bolt (cables) of the layered roof strata can be calculated based on the suspension theory and composite beam theory, which providing a quantitative theoretical basis for the determination of supporting parameters. Finally, as a case, the layered roof strata failure range and supporting parameters of the S1301 auxiliary transportation roadway in Gucheng coal mine are calculated.
\end{abstract}

\section{Introduction}

With the continuous innovation of energy mining technology [1], the support technology of roadway is also constantly innovating. However, due to the complex formation and changeable characteristics of the coal seam, the characteristics of the roadway roof strata are complex and changeable, which makes the stability control of roadway layered roof strata very difficult [2-7]. Therefore, it is very important to analyze the surrounding rock pressure and failure characteristics of the layered roof strata.

After excavation, due to the existence of the free surface and unbalanced surrounding rock pressure, the layered roof strata of rectangular coal roadways will bend and deform to the free surface. If the length and pretightening force of the bolt (cable) are not adequate, the layered roof strata in coal roadways will separate and even collapse $[8,9]$. The study on the deformation mechanism and the supporting parameters of layered roof strata mainly depend on simulation tests, numerical simulations, and field measurements rather than theoretical analysis [10-13]. Zhang et al. [14] studied on the mining instability characteristics and failure modes of the layered roof with three types of weak intercalation which depended on simulation tests and proposed the control principle of the roadway surrounding rock. Sofianos and Kapenis [15], Sofians [16], and Lin [17] studied on the stability and deformation failure process of the layered roof, which was supported by bolts, based on the discrete element method. Jiang et al. [18] classified the roadways compound layered roof into seven types. The classification scheme of roof caving possibility was established, and the hidden danger level of the typical roadway compound layered roof structure was divided.

Based on the composite beam theory and elastic foundation beam model $[6,19-21]$, the deformation characteristics of the layered roof strata in rectangular roadways are analyzed in this study. Based on the Mohr-Coulomb theory, this paper gives the failure criteria of the layered roof strata, and the failure range of the layered roof strata is obtained. Finally, we can calculate the length and pretightening force 
of the bolt (cable) based on the suspension theory and composite beam theory, which provides a quantitative theoretical basis for the determination of the supporting parameters.

\section{Theoretical Background}

2.1. Problem Definition. As the length of the roadway is far larger than the section size, the analytical model is idealized as a plane strain problem. This study assumes that the compound layered roof of roadways are composed of $n$-layer strata, numbered $1,2 \cdots i \cdots n$ from bottom to top (Figure 1). After excavation, the bending deformation of layered roof strata may lead to separation or interlayer sliding of the compound layered roof. If there is no bolt (cable) support, the failure layered roof strata of coal roadways may lead to roof caving accident. After the application of bolt (cable), the fractured layered roof strata will be suspended in the upper stable roof stratum and form a self-stable structure.

According to the above discussion, the first step in calculating the length and pretightening force of the bolt (cable) is to analyze the internal force of the layered roof strata based on the composite beam theory and the elastic foundation beam model. Then, the range of the failure roof can be determined. Finally, the bolt (cable) support parameters are obtained based on the suspension theory and composite beam theory.

Here, we assume that a certain number of layered roof strata in coal roadways form the composite beam structure. For the roadway is a plane-symmetric structure, we can assume that the stress and deformation of the layered roof are also symmetric. Thus, the right part of the layered roof strata relative to the symmetrical axis is taken as the analysis object. Based on the elastic foundation beam theory [14], the composite elastic foundation beam model and its coordinate system are established (Figure 1).

Here, $q$ is the load on the composite elastic foundation beam structure, $l$ is half of the roadway width, $\sigma_{H}$ is the horizontal stress, and $k$ is the foundation characteristic coefficient of the elastic foundation beam.

2.2. Basic Equations. The Winkler hypothesis considers that the settlement amount of any unit point in the foundation surface is proportional to the pressure. Therefore, the foundation counterforce of the elastic foundation beam can be determined as follows:

$$
R=-k Y \text {, }
$$

where $Y$ is the settlement amount of the foundation, namely, the bending amount of the foundation beam, $k=k_{0} b$, where $b$ is the width of the beam, $b=1 \mathrm{~m}$, and $k_{0}$ is the Winkler foundation coefficient.

According to the above simplifications and the equilibrium conditions, the deformation differential equation of the composite elastic foundation beam is

$$
\begin{cases}\mathrm{EI} \frac{d^{4} Y}{d x^{4}}=q+\gamma h, & 0 \leq x \leq l, \\ \mathrm{EI} \frac{d^{4} Y}{d x^{4}}=q+\gamma h-k Y, & l \leq x<\infty\end{cases}
$$

where EI is the bending stiffness of the composite elastic foundation beam, which can be obtained using formula (3), $q$ is the load on the composite elastic foundation beam, $\gamma$ is the unit weight of the composite elastic foundation beam, and $h$ is the thickness of the composite elastic foundation beam.

$$
\mathrm{EI}=\sum_{i=1}^{n} \int_{y_{i}}^{y_{i-1}} E_{i}(y-\Delta)^{2} d A,
$$

where $E_{i}$ is the elastic modulus of the $i$ th roof stratum in the composite elastic foundation beam, $y$ is the ordinate of any point in the composite elastic foundation beam, $y_{i}$ is the ordinate of the upper boundary of the $i$ th roof stratum, and $\Delta$ is the ordinate of the neutral axis, which can be calculated using the following equation:

$$
\Delta=\frac{\sum_{i=1}^{n} \int_{y_{i}}^{y_{i-1}} E_{i} y d A}{\sum_{i=1}^{n} \int_{y_{i}}^{y_{i-1}} E_{i} d A} .
$$

According to the relationship between the bending, rotation angle, moment, and shearing force of composite elastic foundation beam, the deflection, moment, and shearing force are calculated as follows:

$$
\left\{\begin{array}{l}
\theta=\frac{d y}{d x}=Y^{\prime} \\
M=-\mathrm{EI} \frac{d^{2} y}{d x^{2}}=-\mathrm{EI} Y^{\prime \prime} \\
F_{s}=-\mathrm{EI} \frac{d^{3} y}{d x^{3}}=-\mathrm{EI} Y^{\prime \prime \prime}
\end{array}\right.
$$

where $\theta$ is the rotation angle, $M$ is the moment, and $F_{s}$ is the shearing force of any section of the composite elastic foundation beam.

For the model is a symmetric structure, the rotation angle and shearing force are zero at the symmetrical axis $(x=0)$. Moreover, for the excavation influence of the roadway is relatively limited, the rotation angle is zero at infinity $(x \longrightarrow \infty)$. These conditions are expressed as follows:

$$
\begin{cases}Y^{\prime}=Y^{\prime \prime \prime}=0, & x=0, \\ Y^{\prime}=0, & x \longrightarrow \infty .\end{cases}
$$

Considering the continuity of analytical solutions, the bending, rotation angle, moment, and shearing force should be continuous while $x=l$; thus, the continuity condition can 


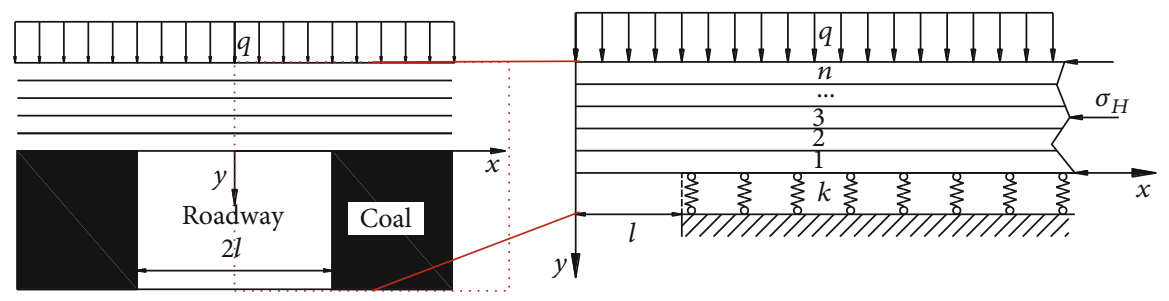

Figure 1: Analysis model of layered roof strata in coal roadway.

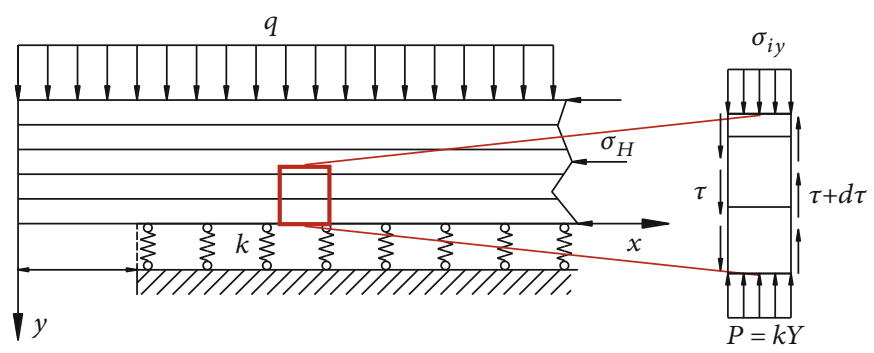

FIgURE 2: The analysis object of the composite beam and its force in the vertical direction.

TABLE 1: Rock properties of the roadway roof strata.

\begin{tabular}{lccc}
\hline Rock strata & Lithology & $\begin{array}{c}\text { Depth } \\
(\mathrm{m})\end{array}$ & $\begin{array}{c}\text { Thickness } \\
(\mathrm{m})\end{array}$ \\
\hline $\begin{array}{l}\text { The 8th roof } \\
\text { stratum }\end{array}$ & Siltstone & 601.32 & 1.89 \\
$\begin{array}{l}\text { The 7th roof } \\
\text { stratum }\end{array}$ & $\begin{array}{c}\text { Medium } \\
\text { sandstone }\end{array}$ & 605.02 & 3.70 \\
$\begin{array}{l}\text { The 6th roof } \\
\text { stratum }\end{array}$ & Fine sandstone & 606.27 & 1.25 \\
$\begin{array}{l}\text { The 5th roof } \\
\text { stratum }\end{array}$ & Siltstone & 607.82 & 1.55 \\
$\begin{array}{l}\text { The 4th roof } \\
\text { stratum }\end{array}$ & Fine sandstone & 609.72 & 1.90 \\
$\begin{array}{l}\text { The 3rd roof } \\
\text { stratum }\end{array}$ & $\begin{array}{c}\text { Medium } \\
\text { sandstone }\end{array}$ & 612.02 & 2.30 \\
$\begin{array}{l}\text { The 2nd roof } \\
\text { stratum }\end{array}$ & Fine sandstone & 614.47 & 2.45 \\
$\begin{array}{l}\text { The 1st roof } \\
\text { stratum }\end{array}$ & Sandy mudstone & 615.29 & 0.82 \\
$3 \#$ coal & \multicolumn{1}{c}{ Coal } & 621.80 & 6.51 \\
\hline
\end{tabular}

TABLE 2: Mechanical parameters of coal and rock.

\begin{tabular}{lcccccc}
\hline Lithology & $\begin{array}{c}E \\
(\mathrm{GPa})\end{array}$ & $\begin{array}{c}\gamma(\mathrm{kN} / \\
\left.\mathrm{m}^{3}\right)\end{array}$ & $\begin{array}{c}k(\mathrm{GN} / \\
\left.\mathrm{m}^{2}\right)\end{array}$ & $\begin{array}{c}R_{t} \\
(\mathrm{MPa})\end{array}$ & $\begin{array}{c}R_{c} \\
(\mathrm{MPa})\end{array}$ & $\begin{array}{c}\varphi \\
\left({ }^{\circ}\right)\end{array}$ \\
\hline $\begin{array}{l}\text { Medium } \\
\text { sandstone }\end{array}$ & 18.96 & 27.18 & -- & 5.37 & 62.3 & 37.3 \\
$\begin{array}{l}\text { Fine } \\
\text { sandstone }\end{array}$ & 11.1 & 26.79 & -- & 3.01 & 50.6 & 35.2 \\
$\begin{array}{l}\text { Siltstone } \\
\begin{array}{l}\text { Sandy } \\
\text { mudstone }\end{array}\end{array}$ & 10.08 & 26.13 & -- & 2.97 & 50.2 & 33.3 \\
Coal & 10.59 & 26.23 & -- & 2.57 & 26.65 & 32.1 \\
\hline & 1.29 & 14.60 & 0.06 & 0.57 & 5.3 & 30.1 \\
\hline
\end{tabular}

be expressed by the following equations:

$$
\left\{\begin{array}{l}
\lim _{x \longrightarrow l_{+}} Y(x)=\lim _{x \longrightarrow l-} Y(x), \\
\lim _{x \longrightarrow l^{+}} Y^{\prime}(x)=\lim _{x \longrightarrow l^{-}} Y^{\prime}(x), \\
\lim _{x \longrightarrow l_{+}} Y^{\prime \prime}(x)=\lim _{x \longrightarrow l_{-}} Y^{\prime \prime}(x), \\
\lim _{x \longrightarrow l_{+}} Y^{\prime \prime \prime}(x)=\lim _{x \longrightarrow l_{-}} Y^{\prime \prime \prime}(x) .
\end{array}\right.
$$

\section{Results}

3.1. Deformation and Internal Force. The general solution of the differential equation (formula (2)) that satisfies the boundary condition (formula (6)) can be expressed as follows:

$Y= \begin{cases}\frac{q+\gamma h}{24 \mathrm{EI}} x^{4}+A_{1} x^{2}+A_{2}, & l \leq x<\infty, \\ e^{-\beta(x-l)}\left[B_{1} \cos (\beta(x-l))+B_{2} \sin (\beta(x-l))\right]+\frac{q+\gamma h}{k}, & 0 \leq x \leq l,\end{cases}$

where $A_{1}, A_{2}, B_{1}$, and $B_{2}$ are undetermined constants that can be determined by the continuity conditions, formula (7). $\beta$ is the characteristic coefficients, which can be expressed as

$$
\beta=\sqrt[4]{\frac{k}{4 \mathrm{EI}}} .
$$

According to the continuity conditions (formula (7)), the undetermined constants of formula (8) can be expressed as 


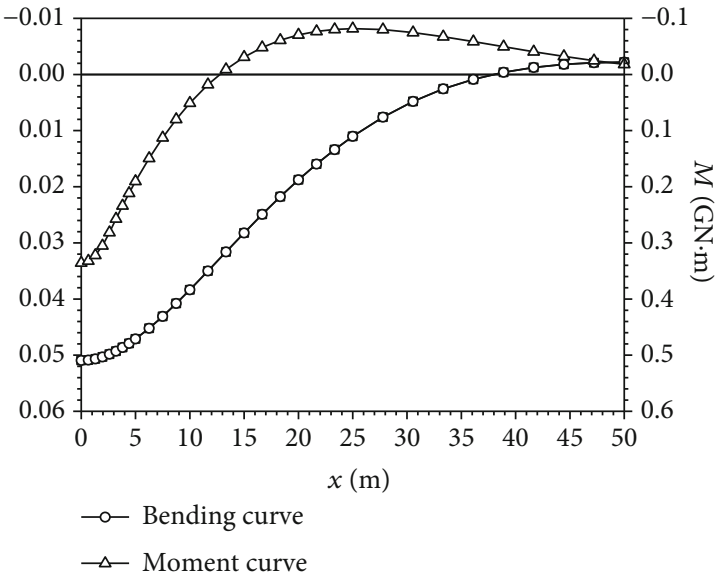

FIGURE 3: Deflection and bending moment curve of composite beam.

follows:

$$
\left\{\begin{array}{l}
A_{1}=-\frac{q+\gamma h}{12 \mathrm{EI}} \frac{\beta^{2} l^{3}+3 \beta l^{2}+3 l}{\beta^{2} l+\beta}, \\
A_{2}=\frac{q+\gamma h}{24 \mathrm{EI}} \frac{\beta^{3} l^{4}+4 \beta^{2} l^{3}+6 \beta l^{2}+6 l}{\beta^{3}}+\frac{q+\gamma h}{k}, \\
B_{1}=\frac{q+\gamma h}{12 \mathrm{EI}} \frac{2 \beta^{2} l^{3}+6 \beta l^{2}+3 l}{\beta^{4} l+\beta^{3}}, \\
B_{2}=-\frac{q+\gamma h}{12 \mathrm{EI}} \frac{2 \beta^{2} l^{3}-3 l}{\beta^{4} l+\beta^{3}} .
\end{array}\right.
$$

In fact, the bending expressed by formula (8) includes two parts: the deformation caused by excavation and the initial deformation caused by the initial surrounding rock stress. Therefore, the deformation caused by excavation can be obtained as follows:

$$
Y_{e}= \begin{cases}\frac{q+\gamma h}{24 \mathrm{EI}} x^{4}+A_{1} x^{2}+A_{2}-\frac{q+\gamma h}{k}, & 0 \leq x \leq l, \\ e^{-\beta(x-l)}\left[B_{1} \cos (\beta(x-l))+B_{2} \sin (\beta(x-l))\right], & l \leq x<\infty .\end{cases}
$$

According to formulas (5) and (8), the moment and shearing force value of the composite elastic foundation beam are obtained as follows:

$M= \begin{cases}-\frac{q+\gamma h}{2} x^{2}-2 A_{1} \mathrm{EI}, & 0 \leq x \leq l, \\ -2 \beta^{2} \mathrm{EI}^{-\beta(x-l)}\left(B_{1} \sin (\beta(x-l))-B_{2} \cos (\beta(x-l))\right), & l \leq x<\infty,\end{cases}$

$F_{s}= \begin{cases}-(q+\gamma h) x, & 0 \leq x \leq l, \\ -2 \beta^{3} \mathrm{EI}^{-\beta(x-l)}\left(\left(B_{2}-B_{1}\right) \sin (\beta(x-l))+\left(B+B_{2}\right) \cos (\beta(x-l))\right), & l \leq x<\infty .\end{cases}$

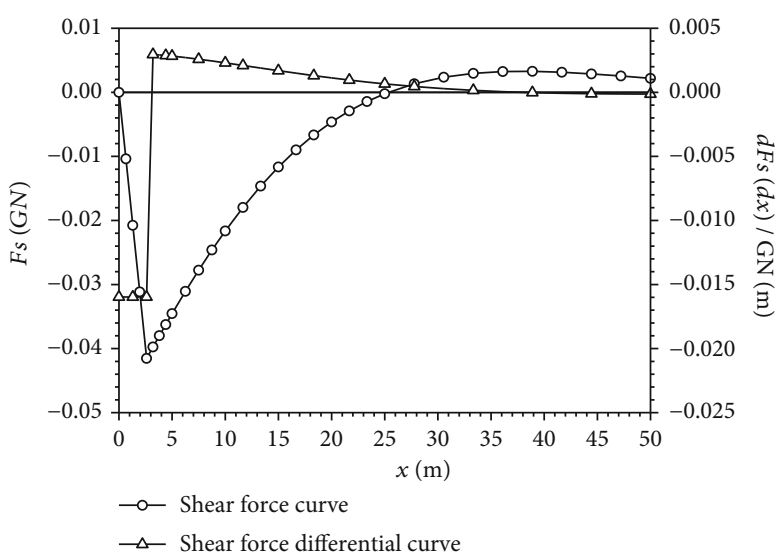

FIgURE 4: Shear force of composite beam and its differential curve.

3.2. Internal Force and Failure Analysis. According to the theory of the key stratum, the load of any strata in the compound layered roof generally affected by its adjacent strata in addition to itself. According to the definition and deformation characteristics of key stratum, when the key stratum deflects, the strata on the key stratum will undergo collaborative deformation, and the failure of the key stratum will lead to the synchronous failure of the strata on the key stratum. Practice shows that there are several key strata that play a major role in the stability control of the roadway, and there is a key stratum that plays a decisive role. Therefore, in order to calculate the failure range of the overlying strata, this article assume that the strata within the control range from the first key stratum to the decisive key stratum form the composite beam structure. Firstly, we assume that the first key stratum is the decisive key stratum. If the calculation result shows that the decisive key stratum is a failure and the composite beam structure does not meet the requirements of roadway stability, then we assume that the second key stratum is the decisive key stratum, and so on. The load $(q)$ on the composite elastic foundation beam structure is the overlying rock strata gravity. Based on this hypothesis and idealization, the bending and deformation of the layered roof strata in coal roadways are calculated.

According to the deduction process of the bending normal stress and the uniaxial compression stress of a beam, the positive stress of any point of the roadway compound layered roof can be obtained as follows:

$$
\sigma_{i}=-M \frac{E_{i}(y-\Delta)}{\mathrm{EI}}+\sigma_{H}
$$

According to the deduction process of the bending shear stress, the shear stress of any point of the roadway compound layered roof can be obtained as follows:

$$
\tau_{i}=\frac{F_{s}}{2 \mathrm{EI}}\left[\sum_{j=1}^{i-1} E_{j}\left(y_{j-1}^{2}-2 y_{j-1} \Delta-y_{j}^{2}+2 y_{j} \Delta\right)+E_{i}\left(y_{i-1}^{2}-2 y_{i-1} \Delta-y^{2}+2 y \Delta\right)\right],
$$

where $y$ is the ordinate of any point in the composite beam 
and $y_{i-1}$ is the ordinate of the upper boundary of layer $i-1$, namely, the ordinate of the lower boundary of layer $i$.

We take part of the composite beam as the analysis object and consider its force balance in the vertical direction (Figure 2).
The normal stress of any point in the vertical direction of the composite beam can be obtained as follows:

$\sigma_{i y}=\left\{\begin{array}{l}\frac{1}{2 \mathrm{EI}} \frac{d F_{s}}{d x}\left[\sum_{j=2}^{i} \int_{y_{j-1}}^{y} E_{j-1}\left(y_{j-2}^{2}-2 y_{j-2} \Delta-y_{j-1}^{2}+2 y_{j-1} \Delta\right) d y+\sum_{j=1}^{i-1} \int_{y_{j-1}}^{y_{j}} E_{j}\left(y_{j-1}^{2}-2 y_{j-1} \Delta-y^{2}+2 y \Delta\right) d y+\int_{y_{i-1}}^{y} E_{i}\left(y_{i-1}{ }^{2}-2 y_{i-1} \Delta-y^{2}+2 y \Delta\right) d y\right], \\ {\left[k Y+\frac{1}{2 \mathrm{EI}} \frac{d F_{s}}{d x}\left[\sum_{j=2}^{i} \int_{y_{j-1}}^{y} E_{j-1}\left(y_{j-2}{ }^{2}-2 y_{j-2} \Delta-y_{j-1}{ }^{2}+2 y_{j-1} \Delta\right) d y+\sum_{j=1}^{i-1} \int_{y_{j-1}}^{y_{j}} E_{j}\left(y_{j-1}{ }^{2}-2 y_{j-1} \Delta-y^{2}+2 y \Delta\right) d y+\int_{y_{i-1}}^{y} E_{i}\left(y_{i-1}{ }^{2}-2 y_{i-1} \Delta-y^{2}+2 y \Delta\right) d y\right], \quad l \leq x \leq \infty .\right.}\end{array}\right.$

In the plane rectangular coordinate system, the Mohr stress circle of any section in the composite beam can be expressed as

$$
\tau^{2}=\left(\frac{\sigma_{i x}-\sigma_{i y}}{2}\right)^{2}+\tau_{i}^{2}-\left(\sigma-\frac{\left(\sigma_{i x}+\sigma_{i y}\right)}{2}\right)^{2},
$$

where $\sigma$ and $\tau$ are the normal stress and shear stress of any section.

According to the Mohr-Coulomb criterion [22], the failure criterion of the layered roof strata can be expressed as follows:

$$
\begin{cases}\tau^{2} \geq\left(\sigma+R_{t}\right)^{2}\left(\frac{1}{2} \sqrt{\frac{R_{c}}{R_{t}}-3}\right)^{2}+\left(\sigma+R_{t}\right) R_{t}, & \frac{R_{c}}{R_{t}} \geq 3 \\ \tau^{2} \geq\left(\sigma+R_{t}\right) R_{t}, & \frac{R_{c}}{R_{t}}<3,\end{cases}
$$

where $R_{c}$ and $R_{t}$ are the compressive and tensile strength of the rock, respectively.

Then, the failure criteria of the roadways layered roof strata can be expressed as follows:

$$
f=\begin{array}{cl}
\left(\frac{1}{2} R_{c}-\frac{1}{2} R_{t}-\sigma_{i x}-\sigma_{i y}\right)^{2}-\left(\frac{R_{c}}{R_{t}}+1\right)\left(\frac{1}{4} R_{c} R_{t}+\frac{1}{4} R_{t}{ }^{2}+\sigma_{i x} \sigma_{i y}-\tau_{i}^{2}\right) \geq 0, & \frac{R_{c}}{R_{t}} \geq 3 \\
\left(\sigma_{i x}+\sigma_{i y}-R_{t}\right)^{2}-4\left(R_{t}^{2}+\sigma_{i x} \sigma_{i y}-\tau_{i}^{2}\right) \geq 0, & \frac{R_{c}}{R_{t}}<3 .
\end{array}
$$

It should be noted that the yielding behavior of the surrounding rock and the failure criteria of the roadways layered roof strata is judged by the stress in the elastic state, which is not an exact elastic-plastic solution.

\subsection{Bolt (Cable) Length and Its Pretightening Force}

3.3.1. Calculation of the Bolt Length. According to the theory of composite beam, the supporting function of the bolts is to provide enough pretightening force to increase the friction force of the failure roof strata and prevent the strata from sliding or even separating. Therefore, the effective length of the bolt should be greater than the thickness of the failure roof strata. The length of the bolt is

$$
L_{b}=L_{b 1}+L_{b 2}
$$

where $L_{b 1}$ is the exposed length of the bolt, which typically takes $0.1-0.2 \mathrm{~m} . L_{b 2}$ is the effective length of the bolt, which is larger than the thickness of the failure roof strata.

3.3.2. Calculation of the Bolt Pretightening Force. According to the composite beam theory, in order to prevent the sliding or even separating, the friction force provided by the bolt should be greater than the maximum shear stress generated by self-weight of the failure roof strata [23-25]. Thus, the bolt pretightening force can be expressed as follows:

$$
F_{b} \geq \frac{3}{4} \frac{\left(\gamma_{i} h_{i}^{\prime}+\sum_{j=1}^{i-1} \gamma_{i} h_{i}\right) l}{\tan \varphi_{\min }\left(h_{i}^{\prime}+\sum_{j=1}^{i-1} h_{i}\right)} a_{b} b_{b}
$$

where $i$ is the number of the failure roof strata; $h_{i}^{\prime}$ is the failure thickness of the $i$ th roof stratum; $a_{b}$ and $b_{b}$ are the transverse and vertical distances of bolts, respectively; $\varphi_{\min }$ is the minimum value of the friction angle of the failure roof strata; and $l$ is half of the roadway width.

3.3.3. Calculation of the Cable Length. According to the theory of composite beam and suspension, the function of cable is to suspend the failure roof strata in the upper stable strata and provide enough pretightening force to increase the friction force of the failure roof strata and prevent the strata from sliding or even separating. Thus, the effective length of the cable is

$$
L_{c 2}=\sum_{j=1}^{i} h_{j}
$$

where $L_{c 2}$ is the effective length of the cable, $i$ is the number 


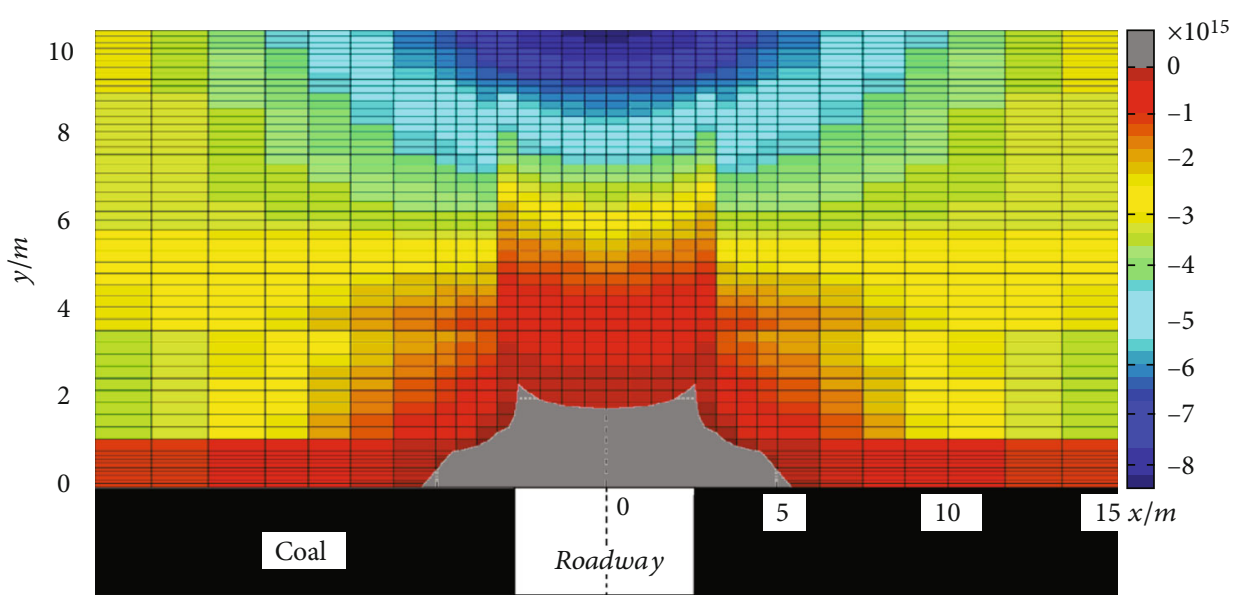

FIgURE 5: Failure factor cloud chart of the composite beam.

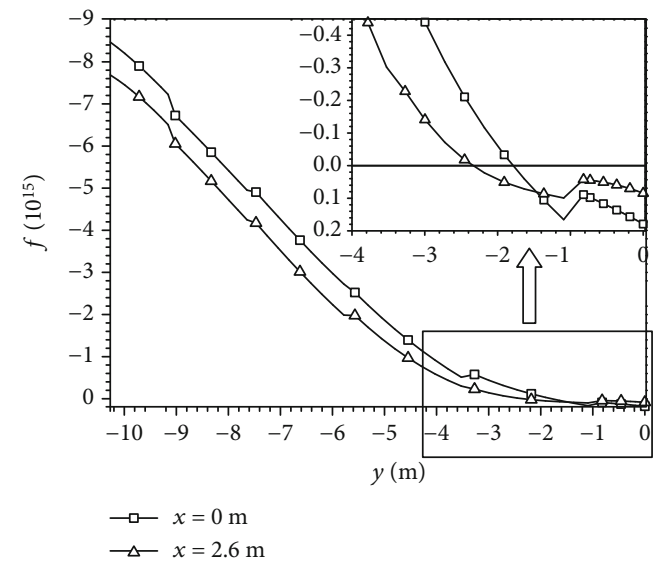

Figure 6: Breaking function curve of the composite beam.

of the failure roof strata, and $h_{j}$ is the thickness of each failure roof stratum. lows:

Therefore, the cable length $\left(L_{c}\right)$ can be determined as fol-

$$
L_{c}=L_{c 1}+L_{c 2}+L_{c 3}
$$

where $L_{c 1}$ is the exposed length of the cable, which typically takes $0.2-0.3 \mathrm{~m} . L_{c 2}$ is the effective length of the cable. $L_{c 3}$ is the anchor length, which can be determined by test according to the pretightening force.

3.3.4. Calculation of the Cable Pretightening Force. The essential role of the cable is to limit the plastic deformation of the surrounding rock and avoid separation or local roof collapse. Therefore, the cable pretightening force should be greater than the equivalent gravity of the failure roof strata, and the friction force provided by the cable support should be greater than the maximum shear stress between the failure roof strata.
Thus, the pretightening force of the cable can be obtained as follows:

$$
F_{c}=\max \left\{a_{c} b_{c} \sum_{j=1}^{i} \gamma_{j} h_{j}, \quad F_{b} \frac{a_{b} b_{b}}{a_{c} b_{c}}\right\} f_{a},
$$

where $F_{c}$ is the pretightening force of the cable, $a_{c}$ is the cables equivalent spacing values, $b_{c}$ is the cables row spacing values, $\gamma_{j}$ is the unit weight of each failure roof stratum, and $f_{a}$ is the safety factor, which typically takes 1.1-1.2.

It should be note that the failure range of the roadways layered roof strata is judged by the stress in the elastic state, and the stress of support structure varies with the development of surrounding rock. Thus, the support parameters are experience results that based on theoretical analysis.

\section{Application}

Taking the S1301 auxiliary transportation roadway of the Chinese Gucheng coal mine as an example, its width is $5.2 \mathrm{~m}(2 l=5.2 \mathrm{~m})$, height is $3.6 \mathrm{~m}(h=3.6 \mathrm{~m})$, and buried depth is $615.3 \mathrm{~m}$. The rock properties of the roadway roof strata is shown in Table 1, and the layered roof strata are numbered $1,2 \ldots 8$ from bottom to top.

According to the geological data and field measurements, the horizontal stress is $9.1 \mathrm{MPa}$. The elasticity modulus, unit weight, foundation coefficient (Winkler's coefficient), and strength parameters of the roof strata are shown in Table 2.

4.1. Determination of Composite Beam Structure and Its Load. According to the key stratum theory, the 1st, 2nd, 3rd, and 4th key strata of the layered roof strata are the 1 st, 2 nd, 3rd, and 7th roof strata, respectively. Due to the low strength of the composite beam structure formed by the first and second key strata, the strata within the control range of the 1st, 2nd, and 3rd key strata can be taken as the research object directly, which means that the 3rd key stratum is the decisive key stratum. Namely, the first to sixth 

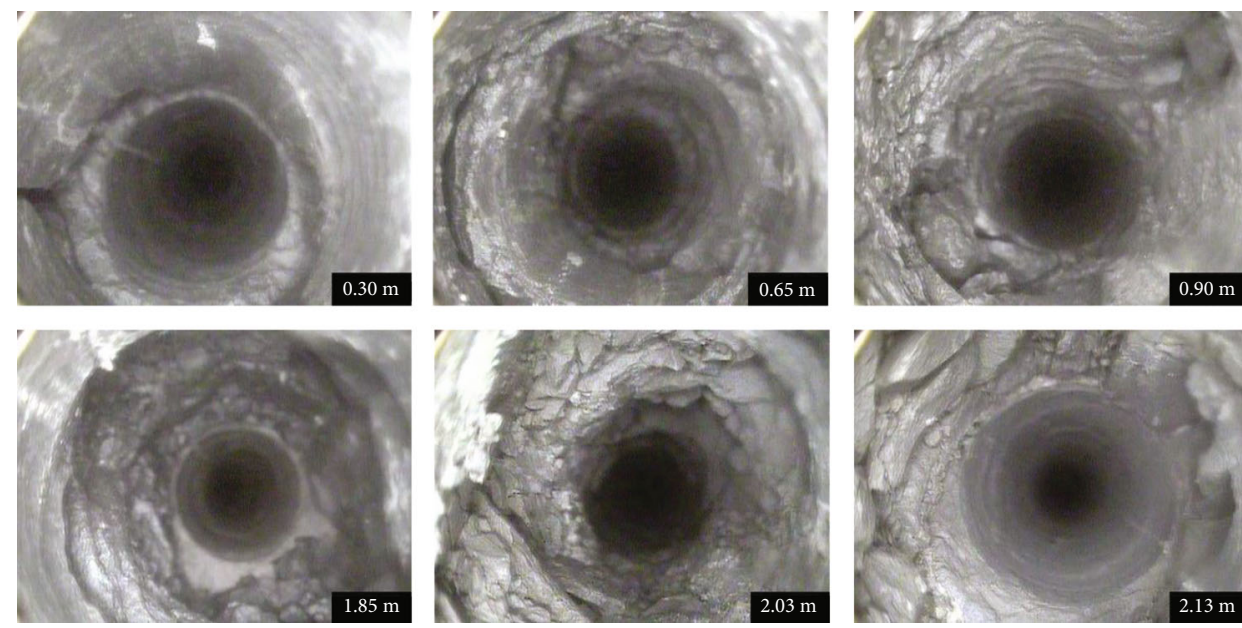

FIGURE 7: Endoscopic research results of roadway roof strata.

roof strata form the composite beam structure, and the load of the overlying strata is $15.7 \mathrm{MPa}$.

4.2. Neutral Axis and Bending Stiffness. The first step is to establish the coordinate system, with the boundary of the roadway roof as its $x$-axis and the central axis of the roadway as its $y$-axis. Then, the neutral axis ordinate and bending stiffness can be obtained $\left(\Delta=-5.01 \mathrm{~m}, \mathrm{EI}=992.3 \mathrm{GN} \cdot \mathrm{m}^{2}\right)$ by substituting the composite beam parameters into formulas (3) and (4).

4.3. Deflection and Internal Force Calculation of Composite Beam. After substituting the bending stiffness (EI), the overlying load $(q)$ and the thickness $(h)$ of the composite beam into formulas (9) and (10), and the coefficients of the bending and internal forces of the composite beam are $\beta=$ $0.06235 \mathrm{~m}^{-1}, \quad A_{1}=-1.6909 \mathrm{~m}^{-1}, \quad A_{2}=0.31719 \mathrm{~m}, \quad B_{1}=$ $0.04984 \mathrm{~m}$, and $B_{2}=0.03649 \mathrm{~m}$.

According to formulas (11), (12), and (13), the deflection, bending moment, shear force, and shear force differential value of the composite beam can be determined, and the curves are shown in Figures 3 and 4.

According to Figures 3 and 4 and formulas (11)and (12), the bending and moment reach their maximum values in the middle of the roadway (while $x=0 \mathrm{~m}$ ), $Y_{e}=5.1 \mathrm{~cm}$ and $M$ $=335.56 \times 10^{6} \mathrm{~N} \cdot \mathrm{m}$, respectively. And the shear force reach its maximum value in the side of roadway (while $x=2.6 \mathrm{~m}$ ), $F_{s}=41.53 \times 10^{6} \mathrm{~N}$.

4.4. Determination of the Failure Strata. According to the above analysis, the thickness of the composite beam is $10.27 \mathrm{~m}$. Taking the composite beam on both sides of the roadway centerline, within $15 \mathrm{~m}$, as the calculation model, the size of the numerical calculation model is $30 \mathrm{~m} \times 10.27$ $\mathrm{m}$. Dividing the calculation model into $31 \times 60$ matrix grid by the software of MATLAB. According to equations (14)-(16), the stress state of each matrix point are obtained, respectively. The failure factors of each matrix point can be obtained by equation (19). The cloud chart of failure factor (as shown in Figure 5) and the curve of failure factor when $x=0 \mathrm{~m}$ and $x=2.6 \mathrm{~m}$ (as shown in Figure 6) can be obtained by MATLAB, which is a Coulomb-Mohr solution. It obvious that the maximum failure depth of the roof strata is $2.3 \mathrm{~m}$ according to Figures 5 and 6 . Thus, according to the key stratum theory, the 1st-2nd layered roof of the roadway may break down. Namely, the effective length of the cable is $L_{2}=3.27 \mathrm{~m}$ according to equation (22).

The endoscopic research technology was used to obtain the broken depth of the roof strata. The criterion for determination of the roof strata failure range is the thickness of the roof strata that loss integrity. The endoscopic research results (Figure 7) show that the roadway roof strata within $2.1 \mathrm{~m}$ is broken at different positions and loss its original integrity. Namely, the failure depth of roadway roof strata is $2.1 \mathrm{~m}$.

4.5. Calculation of Bolt Length and Pretightening Force. According to Figures 5 and 6, the thickness of the damaged roof is $2.3 \mathrm{~m}$, so the effective length of the bolt is $2.3 \mathrm{~m}$, and the length of the bolt is $2.6 \mathrm{~m}$. The transverse and vertical distances of bolts are $0.8 \mathrm{~m} \times 0.8 \mathrm{~m}$ in this roadway. Due to the minimum friction angle of the damaged roof being $32.1^{\circ}$, the pre tightening force of the bolt is $120 \mathrm{kN}$ according to formula (21).

4.6. Calculation of Cable Length and Pretightening Force. According to the above analysis, the 1st-2nd roof strata are likely to be damaged, the effective length of the cable can be determined to be $L_{2}-3,27 \mathrm{~m}$, and the exposed length of the cable are $0.25 \mathrm{~m}$. The spacing values of the cables are $a_{c}=2.6 \mathrm{~m}$ and $b_{c}=0.8 \mathrm{~m}$, and the safety factor is $f_{a}=1.15$. According to formula (24), the pretightening force of the cable should be greater than $210 \mathrm{kN}$. According to the pretightening force of the cable, the anchorage length can be determined by a pull-out test, which is $1.75 \mathrm{~m}$. Thus, the length of the cable is $L=5.3 \mathrm{~m}$. 


\section{Conclusion}

(1) Based on the theory of the elastic foundation beam and key stratum, this paper establishes a simplified analytical model of layered roof strata in a coal roadway. Assuming that the roof strata within the control range from the first key stratum to the decisive key stratum form the composite beam structure. The analytical solution of deformation and internal force of the composite beam structure are obtained

(2) Based on the Mohr-Coulomb theory, the failure criteria of the layered roof strata is obtained; then, the failure range of the layered roof strata is determined. The length and pretightening of bolt (cable) can be calculated according to the suspension theory and composite beam theory, which provide a quantitative theoretical basis for the determination of bolt (cable) supporting parameters and a significant guiding for actual project

(3) Finally, a case is given to demonstrate the analysis and calculation process of the stress and supporting parameters of the layered roof strata in a coal roadway. The cloud chart of the composite beam failure factor and the curve of failure factors (when $x=0$ $\mathrm{m}$ and $x=2.6 \mathrm{~m}$ ) are obtained by MATLAB, which makes the process of determining the failure range of the layered roof strata simpler. Apart from this, the calculation result of the failure range is basically consistent with the endoscopic research results. To some extent, it proves the usefulness of the study. However, the theoretical calculation results still needs more case to verify

(4) It should be noted that the yielding behavior of the surrounding rock and the failure criteria of the roadways compound layered roof is judged by the stress in the elastic state, which is not an exact elasticplastic solution. The supporting parameters are experience results based on theoretical analysis

\section{Data Availability}

The underlying data can be obtained from the corresponding author with the email of 2024613980@qq.com

\section{Conflicts of Interest}

The authors declare that they have no conflicts of interest.

\section{References}

[1] M. Yang, Coal Mine Geology, China Coal Industry Publishing House, Beijing, China, 2006.

[2] M. He, H. Xie, and P. Suping, "Study on rock mechanics in deep mining engineering," Chinese Journal of Rock Mechanics and Engineering, vol. 24, no. 16, pp. 2803-2813, 2005.

[3] H. Manchao, Y. Hesheng, J. Hongwen, W. Fangrong, and J. Haihe, Theory and Practice of Bolt Supporting in China Coal Mines, Science Press, Beijing, China, 2004.
[4] P. Małkowski, Z. Niedbalski, and T. Balarabe, "A statistical analysis of geomechanical data and its effect on rock mass numerical modeling: a case study," International Journal of Coal Science and Technology, vol. 8, no. 2, pp. 312-323, 2021.

[5] P. Małkowski, "The impact of the physical model selection and rock mass stratification on the results of numerical calculations of the state of rock mass deformation around the roadways," Tunnelling and Underground Space Technology, vol. 50, pp. 365-375, 2015.

[6] Q. Zhang, W. He, H.-Y. Zhang, H. Wang, and B.-S. Jiang, "A simple numerical procedure for the elasto-plastic coupling finite strain analysis of circular tunnels in strain-softening rock masses," Computers and Geotechnics, vol. 130, article 103921, 2021.

[7] Q. Zhang, B.-S. Jiang, S. Wang, X. R. Ge, and H.-q. Zhang, "Elasto-plastic analysis of a circular opening in strainsoftening rock mass," International Journal of Rock Mechanics and Mining Sciences, vol. 50, pp. 38-46, 2012.

[8] K. Hongpu and J. Wang, Rock Bolting Theory and Complete Technology for Coal Roadways, China Coal Industry Publishing House, Beijing, China, 2007.

[9] Y. Liang, Control of Surrounding Strata in Deep Mine Roadway and Practice in Huainan Area, China Coal Industry Publishing House, Beijing, China, 2006.

[10] H. P. Kang, P. F. Jiang, and J. F. Cai, "Test and analysis on stress fields caused by rock bolting," Journal of China Coal Society, vol. 39, no. 8, pp. 1521-1529, 2014.

[11] K. Hongpu, J. Tieming, and F. Gao, "Design for pretensioned rock bolting parameters," Journal of China Coal Society, vol. 33, no. 7, pp. 721-726, 2008.

[12] Z. Yingda, "Mechanical mechanism of bolted structure forming in strong fissured surrounding rock," Journal of China Coal Society, vol. 36, no. 9, pp. 1435-1439, 2011.

[13] Z. Yingda, "The mechanics effect of bolt pretension in roadways surrounding rock," Journal of China Coal Society, vol. 33, no. 8, pp. 856-859, 2008.

[14] Z. Long, L. Guichen, and K. Jiaguang, "Influence of soft interlayer location in coal roof on stability of roadway bolting structur," Rock and Soil Mechanics, vol. 32, no. 9, pp. 273-278, 2011.

[15] A. I. Sofianos and A. P. Kapenis, "Numerical evaluation of the response in bending of an underground hard rock voussoir beam roof," International Journal of Rock Mechanics and Mining Sciences, vol. 35, no. 8, pp. 1071-1086, 1998.

[16] A. I. Sofians, "Analysis and design of an underground hard rock voussoir beam roof," International Journal of Rock Mechanics and Mining Sciences \& Geomechanics Abstracts, vol. 33, no. 2, pp. 153-166, 1996.

[17] C. Lin, "Procedure analysis of numerical simulation for the failure mechanism of laminate roof," Chinese Journal of Rock Mechanics and Engineering, vol. 18, no. 4, pp. 392-396, 1999.

[18] L. S. Jiang, N. J. Ma, L. Bai, Y. J. Li, and L. Zhang, "Deformation and failure characteristics and roof caving hidden danger classification of roadways compound roof," Journal of China Coal Society, vol. 39, no. 7, pp. 1205-1211, 2014.

[19] F. Jincheng, Analytical Analysis of Certain Deformation Problems and the Bolt Design in Coal Stope and Caverns, University of Mining \& Technology, Xuzhou China, 2014.

[20] H. Agrawal, S. Durucan, W. Cao, and W. Cai, "Evaluation of parameters affecting the energy accumulation in longwall 
mining," 53rd US Rock Mechanics and Geomechanics Symposium, 2019, p. ARMA-2019-0324, 2019.

[21] Q. Zhang, C.-H. Peng, R.-C. Liu, B.-S. Jiang, and M.-M. Lu, "Analytical solutions for the mechanical behaviors of a hard roof subjected to any form of front abutment pressures," Tunnelling and Underground Space Technology, vol. 85, pp. 128-139, 2019.

[22] Q. Minggao, S. Pingwu, and X. Jialin, "Mine pressure and rock strata control," China University of Mining and Technology Press, pp. 25-26, 2010.

[23] T. Majcherczyk, Z. Niedbalski, P. Małkowski, and Bednarek, "Analysis of yielding steel arch support with rock bolts in Mine Roadways Stability Aspect," Archives of Mining Sciences, vol. 59, no. 3, pp. 641-654, 2014.

[24] Z. Niedbalski, P. Małkowski, and T. Majcherczyk, "Monitoring of stand-and-roof-bolting support: design optimization," Acta Geodynamica et Geomaterialia, vol. 10, no. 2, pp. 215-226, 2013.

[25] F. Qiang, L. Weiwei, F. Shenggang, J. Binsong, and S. Linpo, "Analytical solution for deformation and internal force of hard roof in stope based on elastic foundation beam," Journal of Mining \& Safety Engineering, vol. 34, no. 2, pp. 342-347, 2017. 